\title{
Relation between Clinical Decision Making and Professional Values among Nurses at Critical Care Units
}

\author{
1. B.Sc. Nursing. \\ 2. Professor of Nursing Administration, Faculty of Nursing - Assuit University. \\ 3. Professor of Nursing Administration, Faculty of Nursing -Minia University. \\ 4. Lecturer of Nursing Administration, Faculty of Nursing -Minia University.
}

Abeer Sayed Abdelgawad Dakhly(1); Fatma Rushdy Mohamed(2); Safaa M. Abdelrahman(3); Amira Mostafa Fahmy(4)

\begin{abstract}
Background: Effective clinical decision-making is important for the nurses and their employing organizations. Moreover developing nursing professional values is important because of promotion of care quality, increase of patient's understanding, increase of job satisfaction and retention of nursing staff. Aim of the study: to assess relation between clinical decision making and professional values among nurses at critical care units. Research design: A descriptive correlational research design was used. Subjects: Convenience sample, the study subjects were included all staff nurses working at Dairout central Hospital at critical care units during the period of data collection with total number (no.=122). Setting: The study was conducted on critical care units at Dairout central Hospital. Tools of data collection: included two; first tool" Clinical Decision Making Scale" and $2^{\text {nd }}$ the second tool 'Nursing Professional Value Scale". Results: (77.9\%) of studied nurses have high level of clinical decision-making; and (76.2\%) of them have high level of professional values Conclusion: there were positive strong relation between nurses clinical decision making and their professional values. Recommendations: Training program for nurses about decision making skill, moreover training program for nurses about professional values, also further studies about relationship between professional values and clinical decision making among nurses working at general wards.
\end{abstract}

Keywords: Clinical decision-making, Nurses, Professional Values.

\section{Introduction}

Global health is undergoing wide changes. These changes embrace developments in technology and in developing new methods for patient care. These advances in technology have led to an increase in the complexity of nurses' decision making particularly in critical care areas where nurses usually care for patients with multiple problems (Alasad et al., 2015). Indeed in critical care settings clinical decisions are frequently made in busy, stressful environment where there are competing demands and frequent distractions. Nurses need to make their decisions quickly and accurately to prevent the deterioration of patient condition to a life threatening situation. In addition, dealing with sophisticated new technology, such as cardiac monitor, highly unstable and seriously ill patients with lack of resources, a great burden is put on intensive care nurses to find the best clinical choices and affect their decision making abilities (Maharmeh et al., 2016).

Moreover Clinical Decision Making (CDM) skill is essential in the implementation of nursing knowledge and reflecting on patient care (Edeer\& Sarıkaya, 2015). Clinical decision making is a continuous process, where data are gathered, interpreted, and evaluated to select appropriate choice of action (Tiffen et al., 2014). All stages of clinical decision-making are very important to improve clinical performance of nurses. But it is very complex process due to fast amount of information to be processes and uncertainty of the environment (Kozlowski et al., 2017).

Nurses need to make their decisions quickly and accurately to prevent the deterioration of patient condition to a life threatening situation (Ludin, 2018). Clinical decisions are influenced by many factors as stress, experience, education, assertiveness, personal beliefs and values, and role values and levels of appointment. There is a variety of influences to clinical decision making. These include the importance of education and experience in clinical decision-making and less often level of appointment, age and areas of practice (Kozlowski et al., 2017).

Nurses in critical care areas make many critical decisions. Although the professional role of nurses has extended and become more responsible, these added responsibilities serving for wider decision making. Decisions are more difficult when tasks are more complex; however the process of decision making becomes easier and manageable when the nurses become more experienced (Maharmeh et al., 2016).

Professional values are a cornerstone in nursing practice. They constitute the base upon which decisionmaking is built. Additionally, they might affect nurses' organizational commitment. Nonetheless, there is a paucity of nursing research examining the inter-relations among professional values, decision-making, and organization commitment. This study is an attempt to clarify these relationships, and fill the related knowledge gap (Green, 2020).

Nurses' professional values are important because they affect the decisions made in caring for patients. Nurses need to be aware of their professional values and at the same time be able to care for patients who have different values. An awareness of professional values, cultural differences, and bases help to avoid ineffective communication in stressful situations (Elsheikh \& Naga, 2021).

The application of professional values by nurses in their practice is associated with better quality of patient care. They have a positive impact on nurses' judgment and choices in their care for patients, and their decisions and actions, with compliance to standards. Professional values also help nurses to identify resolutions for ethical problems when making decisions. The decision should be taken in the light of the nursing professional values, and taking into consideration the 
aftereffects of such decision and related nurse accountability (Wright et al., 2020).

The use of professional values in nursing practice helps to increase the quality of patients care, In addition to; increase nursing satisfaction, retention and commitment to the organization. During clinical training nursing student found themselves not have enough experience to cope with a highly dynamic and intense clinical environment. They need to be equipped with common professional nursing values such as caring, activism, trust, professionalism and justice during their undergraduate education. The acquirement of these values helps them to adhere to nursing's standards in today's complex healthcare environment (Jahromi et al., 2020).

\section{Significance of the Research:}

Understanding of CDM of nurses will decrease nurse's turnover, improve organizational productivity and improve patient outcome. As improved CDM afford greater protection against litigation and support quality management in accordance with professional values. Critical care nurses are frequently confronted with patient experiencing rapidly changing health status, and often intervene in critical situations with required immediate CDM in accordance with professional values, but very little research explores the relation between CDM and professional values among nurses in Egypt (Langabeer \& Helton, 2016).

During the researcher work in Dairout central Hospital, observed nurses worked in the critical units made decisions frequently in busy, stressful environment where there are competing demands and frequent distractions. Nurses need to make their decisions quickly and accurately to prevent the deterioration of patient condition to a life and the professional value influence their decisions. So, it is helpful to investigate relation between clinical decision making and professional values among nurses at critical care units.

A previous study in hospitals of a medical university in Iran identified that there was link between professional values and CDM: as nurses are expected to be aware of professional values and apply them to their decision making while dealing with such ethical problems (Poorchangizi, et al, 2017). In additional, according to recent study done by Abou Ramadan and El- demerdash, ( 2017) conducted at faculty of nursing at Tanta university, Egypt to identified relationship between professional values and decision making among nursing student and concluded that more than fifty percent of nursing student at Tanta Faculty of nursing had high level of Professional Values. While, more than seventy of them had moderate level of clinical decision-making. Therefore, there is a need to conduct this study .

\section{The aim of the research:}

The aim this of research is to assess relation between clinical decision making and professional values among nurses at critical care units.

\section{Research questions}

- What are the levels of decision-making and professional values among nurses at the Critical Care Units?

- Is there a relation between clinical decision-making and professional values among the nurses at the Critical Care Units?
- Has personal data an effect on clinical decisionmaking and professional values among nurses at Critical Care Units?

\section{Subjects and Methods Research Design :}

A descriptive correlational research design was utilized in the present research. Setting

The study was conducted at Dairout central hospital in critical care units as Coronary Care Unit (CCU) and Intensive Care Unit (ICU),Dialysis Unit and Neonatal Intensive Care Unit (NICU).

\section{Subjects}

A convenience sample, the study subjects were included all staff nursing who working at Dairout central Hospital in Critical Care Units during the period of data collection (no. $=122$ ), classified as follows:

\begin{tabular}{|c|c|}
\hline Setting & Number of nurses \\
\hline CCU & 15 \\
\hline ICU & 6 \\
\hline Dialysis & 63 \\
\hline NICU & 38 \\
\hline Total number & $\mathbf{1 2 2}$ \\
\hline
\end{tabular}

\section{Exclusion Criteria:}

Nurses had less than one year in nursing experience and worked on irregular basis on the hospital.

\section{Data Collection Tools:}

Two tools were used in this study as follows: Clinical Decision-making Scale and Nursing Professional Value Scale.

\section{Tool I: Clinical Decision-making Scale This Scale was included two parts as follows:}

Part I: personal data sheet: it included personal data about staff nurses as; name (optional), age, gender, marital status, residence, educational qualification, department, years of experience and position title.

\section{Part II: Clinical Decision-making Scale (CDMNS):}

This scale was developed by Jenkins, (2001). It was used to measures the nurses' self-perceptions of decision making behaviors currently utilized when working with patients in the clinical setting, consisted of (40-items). Some modifications was done according to the jury committee such change 5 points Likert scale to three points $(1=$ never, $2=$ occasionally, and $3=$ often) for positive statement; the score were be reversed in the negative statements. The negative statements are $(2,4,6,12,13,15,19,21,22,23,24,25,30$, $31,32,34,39$, and 40 ).

\section{Scoring system:}

The scoring system was ranged from 40 to 120 , and it divided into three levels as follow:

- Low clinical decision making ranged from 40 to 66.

- Moderate clinical decision making ranged from 67 to 93.

- High clinical decision making ranged from 94 to 120. 
Tool II: Nursing Professional Value Scale

Developed by Weis and Schank, (2009), to assess level of nurses professional values, It contains 42 statements, the response of each item was scored on five points Likert Scale ranged from where $5=$ most important, $4=$ very important, $3=$ important, $2=$ somewhat important, and $1=$ not important.

\section{Scoring system:}

The total score was calculated by summing of all categories where $\geq 75 \%$ indicated high level of professional values, $74-50 \%$ indicated moderate level of professional values and $<50 \%$ indicated low level of professional values.

\section{Validity of the study scales:}

Tools were tested for the content validity by a jury of three experts in the field of Nursing Administration and necessary modifications were done. The jury composed of three Professors from Faculty of Nursing, Assuit University. Each of the expert panel was asked to examine the instruments for content coverage, clarity, wording, length, format and overall appearance.

\section{Reliability of the study scales}

Reliability of the scales were performed to confirm consistency of tools. The internal consistency measured to identify the extent to which the items of the tools measured the same concept and correlate with each other by Cronbach's alpha test that revealed good internal reliability for the tools; and distributed as follows:

\begin{tabular}{|ll|c|}
\hline & Tools & $\alpha$ \\
\hline$\bullet$ & Clinical Decision-making Scale & 0.910 \\
\hline$\bullet$ & Nursing Professional Value Scale & 0.870 \\
\hline
\end{tabular}

\section{Pilot Study:}

A pilot study was conducted on $10 \%$ of participants as (12) nurse to ascertain the clarity, comprehensiveness and applicability of the tools as well as to estimate the appropriate time required to fill the scales. Based on pilot study there was no modification done, and it was added to final results.

\section{Data Collection Procedures:}

- Official letters to obtain the approval was introduced to Faculty Dean; this letter was included a brief explanation of the objectives of the study.

- Written approvals were obtained from Directors of the Dairout central Hospital, and head nurses of Hospitals after explaining the purpose of the study.

- Scales were translated into Arabic; then collect the jury approval for the scales were obtained to collect data of the research .

- The scales were distributed to all the participants after explaining the purpose and process of data collection. Scales were directly administered and supervised by the researcher.

- The researcher interviewed with study participants through morning .

- Participants were given from 25 to 30 minutes to answer all the scales.

- The data collection was performed from the nurses during the period from the beginning of January 2021 to finished of April 2021).

\section{Administrative design:}

- A written initial approval was obtained from the Research Ethics Committee of the Faculty of Nursing, Minia University.

- An official letter was granted from Faculty Dean, the Director of the Dairout central (distract) Hospital, and Nursing Director Hospital

\section{Ethical Considerations:}

- The participants were informed that their participation in the study was completely voluntary and there was no harm if they not participate in the study .

- Oral consent was obtained from head nurses and staff nurses after explaining the nature and benefits of the study .

- The participants assured that the data of this research will not be reused without second permission. Anonymity and confidentiality were assured.

\section{Statistical analysis}

The collected data was tabulated, computerized, analyzed and summarized by using descriptive statistical tests to test research questions by using SPSS version (25). Qualitative data were expressed as frequency and percentage. Probability (P-value) is the degree of significance, less than 0.05 was considered significant. The smaller the P-value obtained, the more significant is the result $\left(^{*}\right)$ and less than 0.001 was considered highly significant. $(* *)$

\section{Results}

Table (1) Distribution of the study nurses regarding to their personal data (no. $=122)$.

\begin{tabular}{|c|c|c|}
\hline Characteristics & No. & $\%$ \\
\hline \multicolumn{3}{|l|}{ Age } \\
\hline - $20-29$ year & 78 & 63.9 \\
\hline - $30-39$ year & 42 & 34.5 \\
\hline - $\quad>40$ year & 2 & 1.6 \\
\hline \multicolumn{3}{|l|}{ Mean + SD $=28.16+0.372$} \\
\hline \multicolumn{3}{|l|}{ Gender } \\
\hline - $\quad$ Male & 2 & 1.6 \\
\hline - $\quad$ Femlae & 120 & 98.4 \\
\hline \multicolumn{3}{|l|}{ Marital statues } \\
\hline - $\quad$ Single & 2 & 1.6 \\
\hline - $\quad$ Married & 118 & 96.7 \\
\hline - $\quad$ Divorced & 2 & 1.7 \\
\hline \multicolumn{3}{|l|}{ Educational qualifications } \\
\hline - $\quad$ Secondary School of Nursing Diploma & 12 & 9.8 \\
\hline
\end{tabular}




\begin{tabular}{|c|c|c|}
\hline Characteristics & No. & $\%$ \\
\hline Technical Institute of Nursing & 92 & 75.4 \\
\hline Bachelor Degree of Nursing Science & 18 & 14.8 \\
\hline \multicolumn{3}{|l|}{ Years of experience } \\
\hline$<5 \mathrm{yrs}$ & 31 & 25.4 \\
\hline $5-10 \mathrm{yrs}$ & 64 & 52.5 \\
\hline$>10 \mathrm{yrs}$ & 27 & 22.1 \\
\hline \multicolumn{3}{|c|}{ Mean + SD $=8.176+0.352$} \\
\hline \multicolumn{3}{|l|}{ Residence } \\
\hline - Urban & 70 & 57.4 \\
\hline - $\quad$ Rural & 52 & 42.6 \\
\hline
\end{tabular}

Table(1) shows that (63.9\%) of nurses are in the age group (20-29) with mean age $28.16+0.372$ years, $(98.4 \%)$ of them are females, moreover $(96.7 \%)$ of them are married. Concerning the education qualifications, it notes $(75.4 \%)$ of them have technical degree of nursing, $(52.5 \%)$ of them have years of experience range (5-10) years, while (57.4\%) of them from urban area.

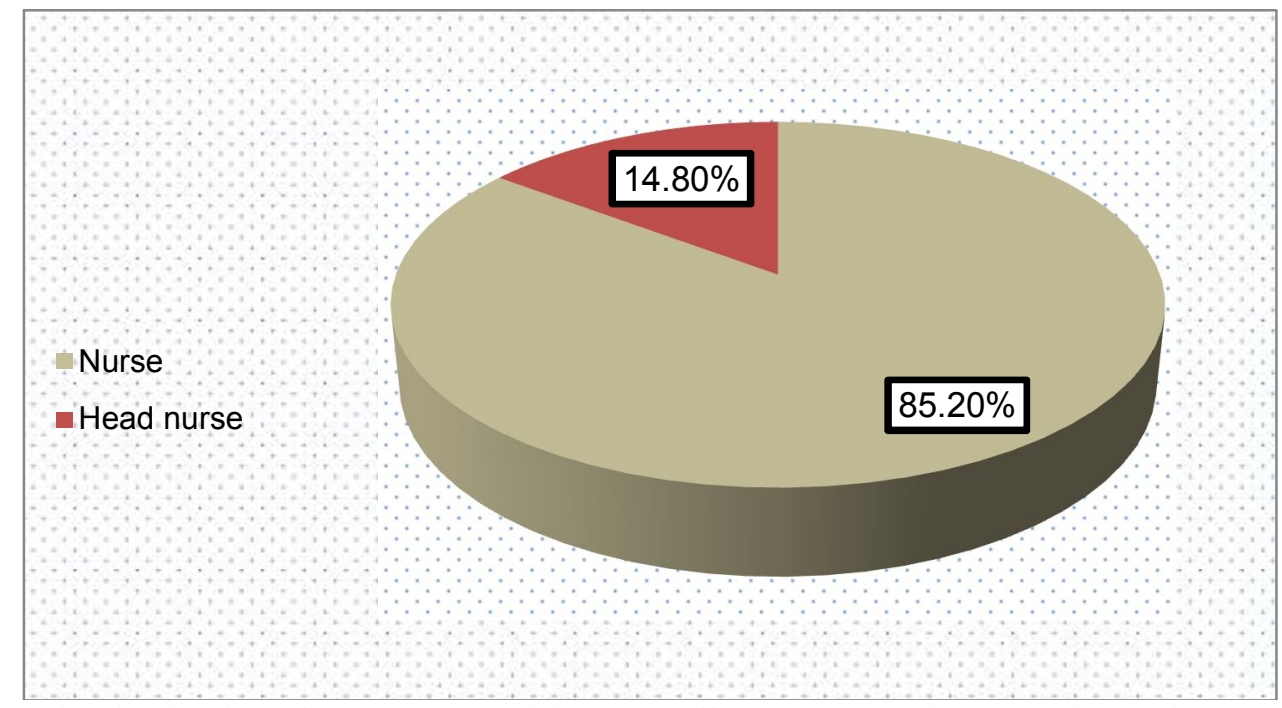

Figure (1) Distribution of the study participants staff nurses regarding to their job title $($ no. $=122)$

Figure (1) indicates that (85.2\%) of study participant have staff nurses, while $(14.8 \%)$ of them have head nurse.

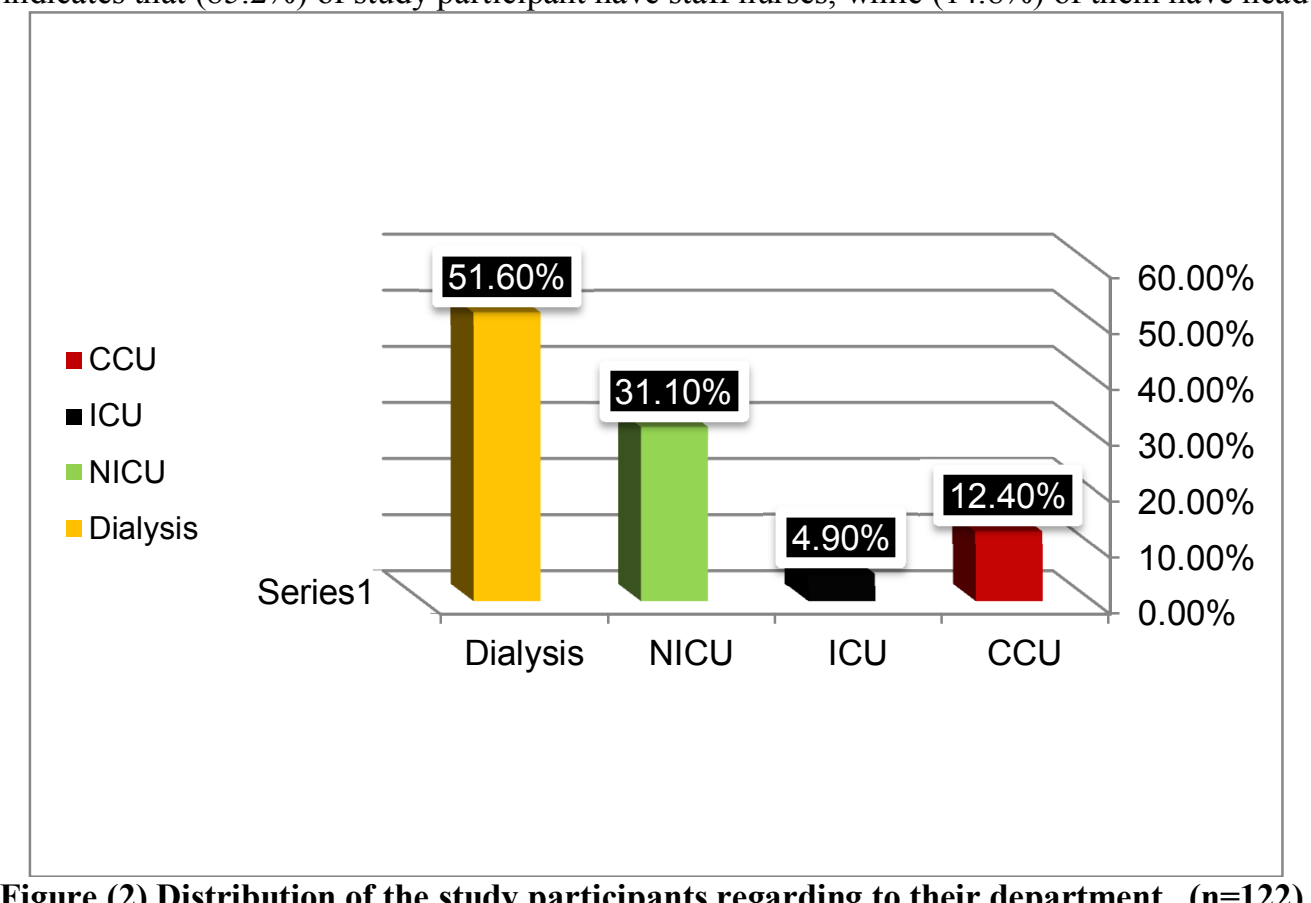

Figure (2) illustrates that (51.6\%) of study nurses are at Dialysis Unit, (31.1\%) of them are at Neonatal Intensive Care Unit. While $(4.9 \%)$ of them are at Intensive Care Unit (ICU). 


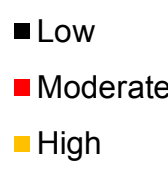

- Low

Moderate $\square$ High

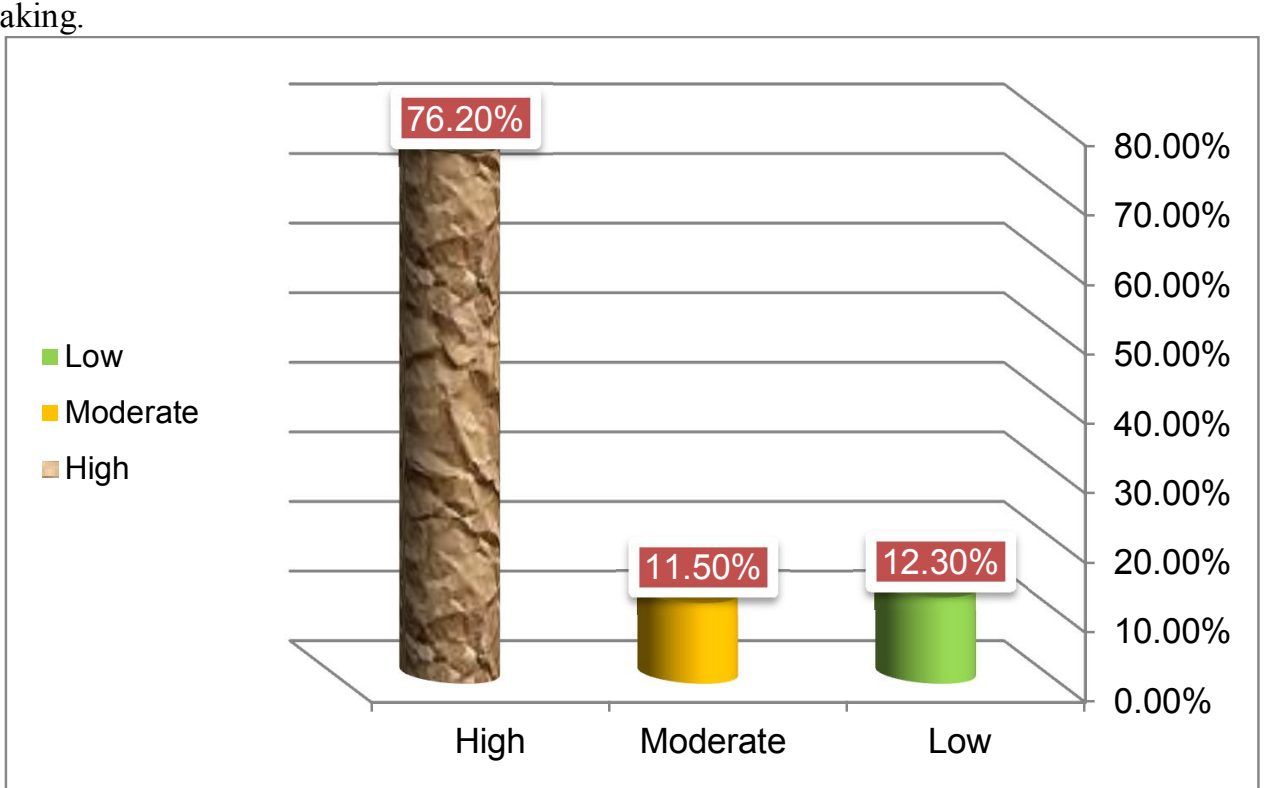

Figure (4) Distribution of the study nurses regarding to their professional value (no.=122).

Figure (4) shows that (76.2\%) of nurses have high level of professional values, while (11.5\%) of them have moderate level of professional values.

Table (2): Relation between personal data and clinical decision making among nurses (no.=122)

\begin{tabular}{|c|c|c|c|c|c|c|c|}
\hline \multirow[t]{2}{*}{ Personal data } & \multicolumn{2}{|c|}{$\begin{array}{c}\text { Low } \\
(\text { no. }=10)\end{array}$} & \multicolumn{2}{|c|}{$\begin{array}{l}\text { Moderate } \\
\text { (no.=17) }\end{array}$} & \multicolumn{2}{|c|}{$\begin{array}{c}\text { High } \\
(\text { no. }=95)\end{array}$} & $\begin{array}{c}\text { Fisher -exact } \\
\text { (p value) }\end{array}$ \\
\hline & No. & $\%$ & No. & $\%$ & No. & $\%$ & No. \\
\hline \multicolumn{8}{|l|}{ Age } \\
\hline - $20-29 \mathrm{yrs}$ & 6 & 4.9 & 16 & 13.1 & 56 & 45.9 & \multirow{3}{*}{$\begin{array}{c}8.94 \\
(.056) \mathrm{NS} \\
\end{array}$} \\
\hline $30-39 y r s$ & 4 & 3.3 & 1 & 0.8 & 37 & 30.3 & \\
\hline - $\quad>40 \mathrm{yrs}$ & 0 & 0 & 0 & 0 & 2 & 1.6 & \\
\hline \multicolumn{8}{|l|}{ Gender } \\
\hline - $\quad$ Male & 0 & 0 & 0 & 0 & 2 & 1.6 & \multirow{2}{*}{$\begin{array}{c}.699 \\
(1.000) \mathrm{NS} \\
\end{array}$} \\
\hline - $\quad$ Female & 10 & 8.2 & 17 & 13.9 & 93 & 76.2 & \\
\hline \multicolumn{8}{|l|}{ Marital status } \\
\hline - $\quad$ Single & 0 & 0 & 0 & 0 & 2 & 1.6 & \multirow{3}{*}{$\begin{array}{c}3.40 \\
(.638) \mathrm{NS} \\
\end{array}$} \\
\hline - $\quad$ Married & 10 & 8.2 & 16 & 13.1 & 92 & 75.4 & \\
\hline - $\quad$ Widow & 0 & 0 & 1 & 0.8 & 1 & 0.8 & \\
\hline \multicolumn{8}{|l|}{ Residence } \\
\hline - $\quad$ Rural & 2 & 1.6 & 9 & 7.4 & 41 & 33.6 & \multirow{2}{*}{$\begin{array}{c}2.74 \\
(.250) \mathrm{NS}\end{array}$} \\
\hline - $\quad$ Urban & 8 & 6.6 & 8 & 6.6 & 54 & 44.3 & \\
\hline
\end{tabular}




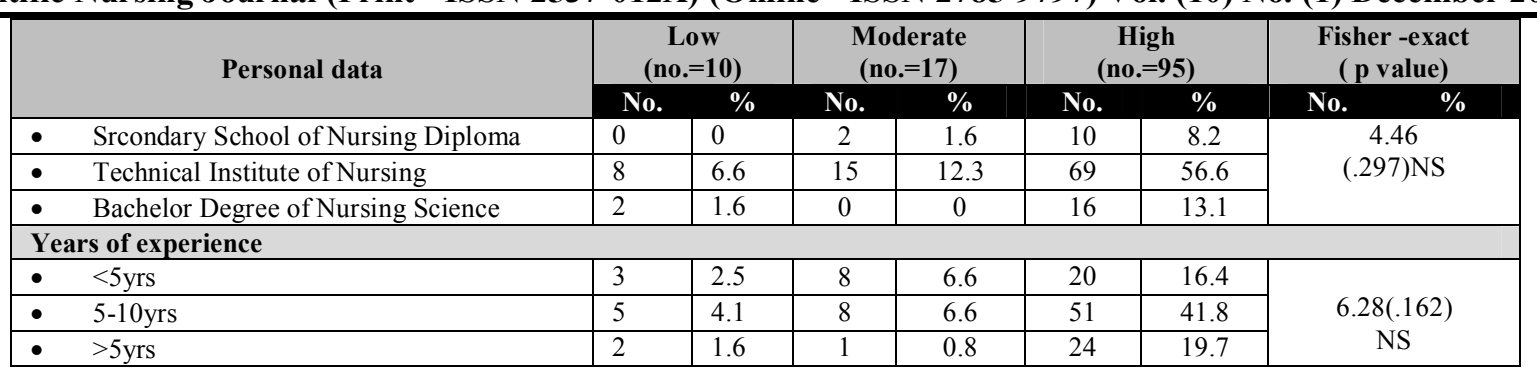

NS: no significant difference in between departments ( $\mathrm{p}$ value $>0.05$ )

Table (2): Explains that no statistically significant differences between personal data and clinical decision making among nurses

Table (3) Relation between personal data and professional value among nurses (no.=122)

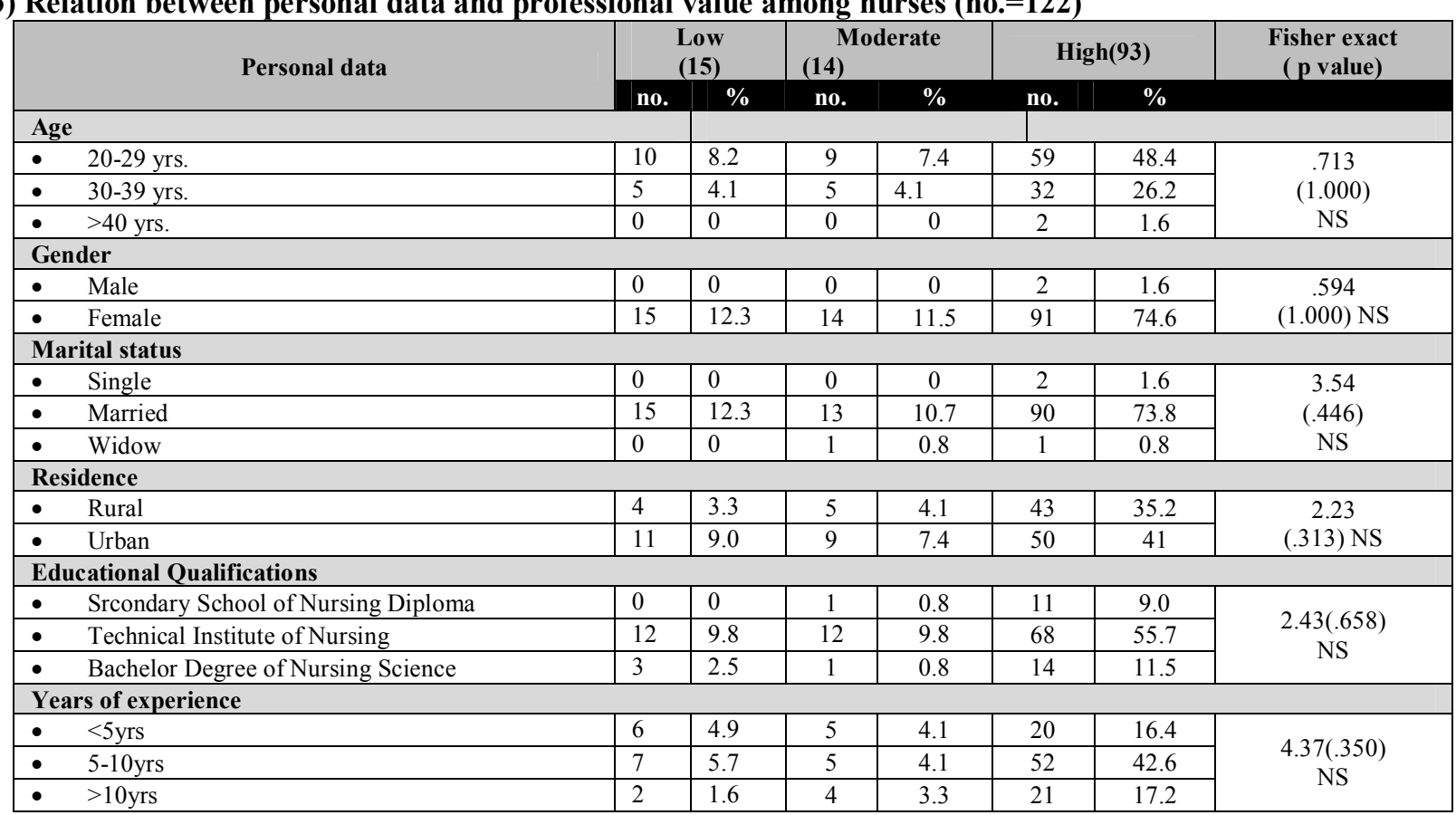

NS: no significant difference in between departments ( $\mathrm{p}$ value $>0.05$ )

Table (3): Mentions that no statistically significant differences between personal data and professional value among nurses

Table (4): Correlation matrix between clinical decision making and professional value among study nurses (no.=122)

\begin{tabular}{|c|c|c|c|}
\hline Variable & Clinical decision making & Professional value \\
\hline Clinical decision making & $\mathbf{R}$ & 1 & $.674^{* *}$ \\
& $\mathbf{P}$ & .000 \\
\hline Professional value & $\mathbf{R}$ & $.674^{* *}$ & 1 \\
\hline & $\mathbf{P}$ & .000 & 1 \\
\hline
\end{tabular}

*Correlation is significant at the 0.01 level (2-tailed) $* \mathrm{p} \leq 0.05$ (significant) $* * \mathrm{p} \leq 0.05$ (highly significant)

PCC: P - value based on Pearson correlation coefficient

Table (4): shows that there is a positive strong correlation between nurses clinical decision making and their professional values with statistically significant differences as $(\mathrm{r}=.674, \mathrm{p} 0.000)$.

\section{Discussion}

The application of professional values by nurses in their practice is associated with better quality of patient care. They have a positive impact on nurses' judgment and choices in their care for patients, and their decisions and actions, with compliance to standards. Professional values also help nurses to identify resolutions for ethical problems when making decisions (Al Shammari et al., 2017).

Regarding the personal data of the studied sample, slightly less than two thirds of nurses were in the age group $(20-29)$ with mean age $28.16+0.372$ years, the majority of them were females and married. Concerning the education qualifications, it noted bout three quarters of them had technical degree of nursing, more than half of them had years of experience ranged (5-10) years, while more than half of $P$ a g e | 129 them from urban area. The majority of them were staff nurses, as well as more than half of them were at Dialysis Unit and the minorities of them were at (ICU).

Regarding clinical decision-making, the present finding explained that more than three quarters of them had high level of clinical decision-making while the minority of them had low level of clinical decision-making. From the researcher point of view the nurses in the Critical Care Units exposure to more critical situations and able to take decision.

This results were supported by Ahmed et al., (2019) who studied and reported that the most of the nurses had high level to make decision. More over this result come in accordance with Mohamed, (2018) who reported that the nurses had high level of the ability to make clinical decision. 
This result come in against with Ghonem \& Abdrabou, (2021)who studied "Professional Values, Clinical Decision-Making, and Organizational Commitment among Nurses: Analytic Cross-Sectional Study" and reported that the nurses in the study settings have high professional values and organizational commitment, with lower decision-making skills.

Regarding professional value, the present study showed that more than three quarters of them had high level of professional values. From the researcher point of view the nurses professional values are a cornerstone in nursing practice and professional values constitute as the base upon which nurses decision-making is built.

This result come in accordance with Ghonem \& Abdrabou, (2021) who reported that the nurses in the study settings have high professional values and organizational commitment, with lower decision-making skills. Moreover study done by Poorchangizi et al., (2019) who reported professional values are the foundation for nursing practice as well as the guidelines for nurses in interacting with patients, colleagues, other professions, and public.

Regarding the relation among personal data, clinical decision-making, and professional value among nurses, the present findings enumerated that no statistically significant differences between personal data and clinical decisionmaking, and professional value among nurses. From the researcher point of view professional value considered the base of nurse decisions regardless nurses age, gender, educational qualifications, and experience.

Similar results showed by Alizadeh et al., (2020) they concluded that, there was no significant difference between the nurses' clinical decision making score with the demographic variables of age and education level or work experience.

Moreover this result contraindicated with Erkus and Dinc, (2018) who reported that nurses had higher scores on perception of professional values, and education level and years of professional experience were associated with higher scores. These findings are inconsistent with those of Cetinkaya-Uslusoy et al., (2017) who studied "Professional values of Turkish nurses" who found that nurses' professional value scores were associated with age, marital status, and position.

Regarding the correlation between clinical decisionmaking and professional value among nurses, the current study showed that there was highly significant relation between clinical decision-making and professional values among nurses. From the researcher point of view the professional values considered the base of clinical decisionmaking

This result come in the line with Abou Ramadan and El-Demerdash, (2017) who studied "The Relationship between Professional Values and Clinical Decision-making among Nursing Student" and reported that nursing students' total clinical decision-making was significantly correlated with their total professional values. Also Poorchangizi et al., (2017) reported that Nurses' perspective on professional values affects decision-making and patient care

But this result consistent with Hoffman et al., (2014) who studied "Barriers to clinical decision-making in nurses in Australia' and found that nurses who holding a professional role value participated more in clinical decision-making than those holding a paramedical role value.

\section{Conclusion}

Based on the findings of this current study, it was concluded that:

About Three quarters of studied nurses have high level of clinical decision-making and professional values. There were no statistically significant differences between personal data and clinical decision-making, and professional value among nurses. Also there was highly statistically significant relation between clinical decision-making and professional values among studied nurses.

\section{Recommendations}

Based on results of the present study the following can be recommended:

- Training program for nurses about decisionmaking skills.

- Training program for nurses about professional values.

- Share staff nurses in conferences, training courses, and decision-making in the organization

- Nurse Manager should provide ongoing support through feedback and positive reinforcement and encouragement of innovative ideas also are the ways of improving nurses' decision-making skills and professional values.

\section{Recommendations for further studies:}

- The relationship between professional values and clinical decision-making among nurses working in different general wards.

- Factors affecting clinical decision-making among nurses and its effects on patient satisfaction.

- Factors affecting professional values among nurses and its effects on patient satisfaction.

\section{References}

(1) Abou Abou Ramadan, A. H., \& El-Demerdash, S. M. (2017). The relationship between professional values and clinical decision making among nursing student. environment, 7, 8

(2) Ahmed, A. A., Abd El-Wahab ,E. A., \& Aly, S. H. (2019). Relationship between Nursing Staff's Decisional Involvement and Their Decision-Making Abilities in Cairo University Hospital. The Medical Journal of Cairo University, 87(March), 407-413.

(3) Al Shammari, F., Grande, R. A. N., Vicencio, D. A., \& Al Mutairi, S. (2017). Nurses' professional values on patient care provisions and decisions. Journal of Nursing Education and Practice, 7(9), 78.

(4) Alasad, J. A., Tabar, N. A., \& Ahmad, M. M. (2015). Patients' experience of being in intensive care units. Journal of Critical care, 30(4), 859-e7.

(5) Alizadeh, I., Salari, A., Ahmadnia, Z., \& Moaddab, F. (2020). An Investigation into Self-efficacy, Clinical Decision-making and the Level of Relationship between them among Nurses in Guilan Province. Journal of Guilan University of Medical Sciences, 29(2), 38-49.

(6) Cetinkaya-Uslusoy, E., Pasl1-Gürdogan, E., \& Aydınlı, A. (2017). Professional values of Turkish nurses: a descriptive study. Nursing ethics, 24(4), 493-501.

(7) Edeer, A. D., \& Sarikaya, A. (2015). Adaptation of clinical decision making in nursing scale to undergraduate students of nursing: the study of reliability and 
validity. International Journal of Psychology and Educational Studies, 2(3), 1-9.

(8) Elsheikh, M., \& Naga, A. E. (2021). Burnout among Egyptian health care workers and its associations. Egyptian Journal of Psychiatry, 42(1), 43.

(9) Erkus, G., \& Dinc, L. (2018). Turkish nurses' perceptions of professional values. Journal of Professional Nursing, 34(3), 226-232.

(10) Green, G. (2020, November). Examining professional values among nursing students during education: A comparative study. In Nursing Forum (Vol. 55, No. 4, pp. 589-594).

(11) Hoffman, K., Duffield, C., \& Donoghue, J. (2014). Barriers to clinical decision making in nurses in Australia. Australian Journal of Advanced Nursing, The, 21(3), 8-13.

(12) Jahromi, M. K., Manesh, E. P., Hejazi, F., Moosavifard, Z. S., \& Poorgholami, F. (2020). Professional values of the nursing students' Perspective in Jahrom University of medical sciences, 2017. Bangladesh Journal of Medical Science, 19(3), 427-432.

(13) Jenkins, H. M. (2001). Clinical decision making in nursing scale. Measurement of nursing outcomes, 1, 33-40.

(14) Kozlowski, D., Hutchinson, M., Hurley, J., Rowley, J., \& Sutherland, J. (2017). The role of emotion in clinical decision making: an integrative literature review. BMC medical education, 17(1), 1-13.

(15) Langabeer II, J. R., \& Helton, J. (2016). Health care operations management: A Systems Perspective. Jones \& Bartlett Publishers.

(16) Ludin, S. M. (2018). Does good critical thinking equal effective decision-making among critical care nurses? A cross-sectional survey. Intensive and Critical Care Nursing, 44, 1-10.

(17) Maharmeh, M., Alasad, J., Salami, I., Saleh, Z., \& Darawad, M. (2016). Clinical decision-making among critical care nurses: A qualitative study. Health, 8(15), 1807.

(18) Ghonem, M. E., \& Abdrabou, M. H. (2021). Professional Values, Clinical Decision-Making, and Organizational Commitment among Nurses: Analytic Cross-Sectional Study. Egyptian Journal of Health Care, 12(1), 707-721 .

(19) Mohamed, N. T. (2018). Relationship between leadership styles and clinical decision-making autonomy among critical care nurses. Egyptian Nursing Journal, 15(2), 102.

(20) Poorchangizi, B., Farokhzadian, J., Abbaszadeh, A., Mirzaee, M., \& Borhani, F. (2017). The importance of professional values from clinical nurses' perspective in hospitals of a medical university in Iran. BMC medical ethics, 18(1), 1-7.

(21) Poorchangizi, B., Borhani, F., Abbaszadeh, A., Mirzaee, M., \& Farokhzadian, J. (2019). Professional Values of Nurses and Nursing Students: a comparative study. BMC medical education, 19(1), 1-7.

(22) Tiffen, J., Corbridge, S. J., \& Slimmer, L. (2014). Enhancing clinical decision making: development of a contiguous definition and conceptual framework. Journal of professional nursing, 30(5), 399-405.

(23) Weis, D., \& Schank, M. J. (2009). Development and psychometric evaluation of the nurses professional values scale-revised. Journal of Nursing Measurement, 17(3), 221-231.

(24) Wright, A. L., Irving, G., \& Selvan Thevatas, K. (2021). Professional values and managerialist practices: Values work by nurses in the emergency department. Organization Studies, 42(9), 1435-1456. 